\title{
Coexisting Heart Failure and Chronic Obstructive Pulmonary Disease: Report of Two Cases Treated with Indacaterol/Glycopyrronium
}

\author{
Eugenio Roberto Cosentino Daniela Degli Esposti Rinaldo Miceli \\ Crescenzio Bentivenga Matteo Landolfo Ilaria Ricci lamino Luca Spinardi \\ Gianluigi Magri Claudio Borghi \\ Cardio-Thoraco-Vascular Department, University Hospital of Bologna, Policlinico S. Orsola-Malpighi, Bologna, Italy
}

\section{Keywords \\ Chronic obstructive pulmonary disease $\cdot$ Heart failure $\cdot$ Indacaterol/glycopyrronium}

\begin{abstract}
Chronic obstructive pulmonary disease (COPD) is a major cause of morbidity and mortality worldwide, and it is associated with a high economic burden. Heart failure shares some general symptoms with COPD; thus, diagnosing COPD is difficult in subjects with a history of heart failure, and spirometry is mandatory for confirmation. Moreover, COPD is a highly prevalent comorbidity negatively impacting the outcome of heart failure patients. We document here the treatment with indacaterol/glycopyrronium in 2 patients with concomitant COPD and heart failure. Overall, the combination of indacaterol and glycopyrronium resulted in a reciprocal potentiation with a maximal bronchodilatory effect.
\end{abstract}

(c) 2018 S. Karger AG, Basel

\section{Introduction}

Chronic obstructive pulmonary disease (COPD) is a major cause of morbidity and mortality worldwide, and it is associated with a high economic burden. In 2014, ap- proximately 15 million Americans were diagnosed with COPD [1]. Its prevalence increases with age, ranging from $2.6 \%$ in adults aged $18-34$ years to $12.3 \%$ in 75 -yearold subjects [1]. It has been reported that $>50 \%$ of adults with some degrees of pulmonary dysfunction ignore their disease; thus, COPD prevalence might even be higher than estimated [2]. COPD is associated with a reduction in the working abilities of the individuals due to functional limitations [3].

Of note, COPD shares some general symptoms with heart failure, and thus diagnosing COPD becomes even more challenging in patients with a history of heart disease. In turn, COPD may be associated with a worsening of heart failure outcomes [4].

We report here the cases of 2 patients with concomitant COPD and heart failure, successfully treated with indacaterol/glycopyrronium for their respiratory disease.

\section{Case Descriptions}

Case 1

We present the case of a 67-year-old man with multiple cardiovascular risk factors (active smoker, arterial hypertension, diabetes mellitus, chronic atrial fibrillation, and hypothyroidism secondary to chronic thyroiditis currently treated with hormonal therapy). In 2014, he was hospitalized for acute respiratory failure, and he received a diagnosis of heart failure. At that time, echocardiography
(C) 2018 S. Karger AG, Basel

E-Mail karger@karger.com

www.karger.com/res
Eugenio Roberto Cosentino

Cardio-Thoraco-Vascular Department, University Hospital of Bologna Policlinico S. Orsola-Malpighi

Via Pietro Albertoni 15, IT-40138 Bologna (Italy)

E-Mail eugenio.cosentino@ aosp.bo.it 
Table 1. Respiratory parameters in patient 1

\begin{tabular}{llc}
\hline & Baseline & 6 months \\
\hline $\mathrm{FEV}_{1}, \%$ & 61 & 89 \\
$\mathrm{FEV}_{1} / \mathrm{FVC}, \%$ & 55 & 95 \\
$\mathrm{CAT}$ score & 16 & 8
\end{tabular}

$\mathrm{FEV}_{1}$, forced expiratory volume in the first second; $\mathrm{FVC}$, forced vital capacity; $\mathrm{FEV}_{1} / \mathrm{FVC}$, Tiffeneau index; CAT, COPD Assessment Test.

Table 3. Respiratory parameters in patient 2

\begin{tabular}{lll}
\hline & Baseline & 6 months \\
\hline $\mathrm{FEV}_{1}, \%$ & 66 & 80 \\
$\mathrm{FEV}_{1} / \mathrm{FVC}, \%$ & 60 & 70 \\
CAT score & 25 & 14 \\
\hline
\end{tabular}

$\mathrm{FEV}_{1}$, forced expiratory volume in the first second; FVC, forced vital capacity; $\mathrm{FEV}_{1} / \mathrm{FVC}$, Tiffeneau index; CAT, COPD Assessment Test

revealed the presence of concentric left ventricular hypertrophy with a preserved ejection fraction of $52 \%$, with relevant valvulopathies affecting both the mitral valve (mild steno-insufficiency) and the aortic valve (mild-to-moderate aortic regurgitation), highly suspicious of rheumatic origin. Another finding was moderate biatrial enlargement. On spirometry, forced expiratory volume in the first second $\left(\mathrm{FEV}_{1}\right)$ was $61 \%$ of the predicted value, with a $\mathrm{FEV}_{1} /$ forced vital capacity (FVC) ratio of $55 \%$; the COPD Assessment Test (CAT) was performed and the final score was 18 . The patient was discharged on the following medications: ramipril 10 $\mathrm{mg}$ /day, bisoprolol $5 \mathrm{mg}$ /day, digoxin $0.125 \mathrm{mg}$ /day, furosemide $50 \mathrm{mg} /$ day, warfarin $5 \mathrm{mg} /$ day, tiotropium bromide $18 \mu \mathrm{g} /$ day, and levothyroxine $75 \mathrm{mcg} /$ day. The patient was re-hospitalized twice in 2015 and 2016 for pneumonia, and initial signs of heart failure were noted, secondary to the progression of the valvular diseases. In particular, the patient presented New York Heart Association (NYHA) functional class III symptoms in 2017 (marked limitation of physical activity, with less than ordinary activity causing fatigue, palpitation, or dyspnea), with a worsened left ventricular function.

The patient was excluded from valve replacement surgery due to anesthesiological risk. Spirometry was unchanged, with a CAT score of 16 .

We decided to add the bronchodilator combination indacaterol/glycopyrronium ( $85 / 43 \mu \mathrm{g} /$ day) to the patient's therapy, and after 6 months with this therapy, his $\mathrm{FEV}_{1}$ improved to $89 \%$ of the predicted value with a $\mathrm{FEV}_{1} / \mathrm{FVC}$ ratio of $75 \%$ and a CAT score of 8 . Additionally, the sinus rhythm was restored with a heart rate of $62 \mathrm{bpm}$, and echocardiography improved.

Tables 1 and 2 depict the results of the main tests performed in our patient at baseline (start of indacaterol/glycopyrronium) and
Table 2. Clinical and laboratory parameters in patient 1

\begin{tabular}{lcc}
\hline & Baseline & 6 months \\
\hline Systolic BP, mm Hg & 131 & 128 \\
Diastolic BP, mm Hg & 76 & 74 \\
Heart rate, bpm & 68 & 69 \\
EF, \% & 52 & 58 \\
BNP, pg/mL & 150 & 100 \\
\hline
\end{tabular}

BP, blood pressure; EF, ejection fraction.

after 6 months of treatment; all parameters were confirmed after further 6 months of follow-up.

Case 2

An 80-year-old woman, who was an active smoker with a history of coronary artery disease, had been treated in 2001 with a coronary angioplasty on the left main coronary artery for moderate stenosis, conditioning angina on exertion.

In 2006 during regular follow-up, she was diagnosed with COPD. Spirometry revealed a $\mathrm{FEV}_{1}$ of $68 \%$ of the predicted value, and she was immediately advised to start a therapeutic regimen combining fluticasone and salmeterol, with clinical benefit. However, in 2014, she experienced several bronchitis exacerbations, needing oral steroid cycles. In 2015, the patient was re-hospitalized for concomitant heart failure, secondary to atrial fibrillation, and pneumonia. Echocardiography revealed hypertensive heart disease with moderate diastolic dysfunction, biatrial enlargement, moderate tricuspid regurgitation with an estimated systolic pulmonary artery pressure of $45 \mathrm{~mm} \mathrm{Hg}$ (normal range $<35 \mathrm{~mm} \mathrm{Hg}$ ); ejection fraction was preserved (54\%). BNP was markedly increased (1,500 pg/mL). After all appropriate treatments, the patient was discharged home with NYHA III with the following therapies: pantoprazole $20 \mathrm{mg} /$ day, amlodipine $5 \mathrm{mg} /$ day, atorvastatin $20 \mathrm{mg} /$ day, allopurinol $300 \mathrm{mg} /$ day, doxazosin $2 \mathrm{mg} /$ day, bisoprolol $5 \mathrm{mg}$ /day, furosemide $125 \mathrm{mg} /$ day, irbesartan $300 \mathrm{mg} /$ day, acetyilsalicylic acid $100 \mathrm{mg} /$ day, 14 units of slow insulin, apixaban $5 \mathrm{mg}$ b.i.d., and the association indacaterol/glycopyrronium at the dose of $85 / 43 \mu \mathrm{g} /$ day.

Importantly, $\mathrm{FEV}_{1}$ at 30 days was $66 \%$ of the predicted value with a Tiffeneau index $\left(\mathrm{FEV}_{1} / \mathrm{FVC}\right)$ of $60 \%$ (normal value $>80 \%$ ). The CAT score was 25. At the 6-month follow-up, we registered some clinical improvements with all the assessed parameters demonstrating a favorable trend (systolic pulmonary artery pressure 30 $\mathrm{mm} \mathrm{Hg}$ with only mild tricuspid regurgitation, $\mathrm{FEV}_{1} 80 \%$ of the predicted value, Tiffeneau index $70 \%$, and CAT score 14 ; Table 3 ), with a persistent NYHA II class. The combination therapy with indacaterol/glycopyrronium was overall well tolerated.

\section{Discussion}

COPD induces several cardiovascular comorbidities and exerts a negative prognostic effect on the outcomes of heart failure patients [4]. We presented 2 cases of pa- 
tients with concomitant COPD and heart failure treated with indacaterol/glycopyrronium for their respiratory disease. The combination of indacaterol and glycopyrronium results in reciprocal potentiation with a maximal bronchodilatory effect [5], by several possible mechanisms.

As already demonstrated in the FLAME and CRYSTAL studies, the combination indacaterol/glycopyrronium is superior to other treatments in improving dyspnea rapidly [6-8]. This quality was also evident in our patients in whom dyspnea was significantly retrieved when the combination was added to the patients' therapies, as expressed by the reduction of the CAT score.

Moreover, several concerns exist about the use of the long-acting beta-agonist (LABA) and long-acting muscarinic antagonist (LAMA) combination in patients with any type of cardiac abnormalities (arrhythmias, heart failure, coronary disease). Caution is recommended in these cases. However, in this report we showed that their use is feasible in patients with cardiac disorders.

\section{Acknowledgement}

The authors thank Luca Giacomelli, $\mathrm{PhD}$, for providing medical writing on behalf of Content Ed Net; this assistance was funded by Novartis Farma SpA.

\section{Financial Disclosure and Conflicts of Interest}

The authors have no conflict of interest directly relevant to this paper.

\section{References}

1 Wheaton AG, Cunningham TJ, Ford ES, Croft JB: Employment and activity limitations among adults with chronic obstructive pulmonary disease - United States, 2013. MMWR Morb Mortal Wkly Rep 2015;64: 289-295.

2 Mannino DM, Gagnon RC, Petty TL, Lydick E: Obstructive lung disease and low lung function in adults in the United States: data from the National Health and Nutrition Examination Survey 1988-1994. Arch Intern Med 2000;160:1683-1689.

3 Patel JG, Nagar SP, Dalal AA: Indirect costs in chronic obstructive pulmonary disease: a review of the economic burden on employers and individuals in the United States. Int J Chron Obstruct Pulmon Dis 2014;9:289-300.

4 Čelutkienė J, Balčiūnas $M$, Kablučko D, Vaitkevičiūtė L, Blaščiuk J, Danila E: Challenges of treating acute heart failure in patients with chronic obstructive pulmonary disease. Card Fail Rev 2017;3:56-61.

5 Cohen JS, Miles MC, Donohue JF, Ohar JA: Dual therapy strategies for COPD: the scientific rationale for LAMA + LABA. Int J Chron Obstruct Pulmon Dis 2016;11:785-797.

6 Wedzicha JA, Banerji D, Chapman KR, Vestbo J, Roche N, Ayers RT, Thach C, Fogel R, Patalano F, Vogelmeier CF; FLAME Investigators: Indacaterol-glycopyrronium versus salmeterol-fluticasone for COPD. N Engl J Med 2016;374:2222-2234.

7 Vogelmeier CF, Gaga M, Aalamian-Mattheis M, Greulich T, Marin JM, Castellani W, Ninane V, Lane S, Nunez X, Patalano F, Clemens A, Kostikas K; CRYSTAL study investigators: Efficacy and safety of direct switch to indacaterol/glycopyrronium in patients with moderate COPD: the CRYSTAL open-label randomised trial. Respir Res 2017;18:140.

8 Mahler DA, Keininger DL, Mezzi K, Fogel R, Banerji D: Efficacy of indacaterol/glycopyrronium in patients with COPD who have increased dyspnea with daily activities. Chronic Obstr Pulm Dis 2016;3:758-768. 